\title{
Novos polimorfismos no gene da obesidade em raças divergentes de suínos
}

\author{
[Polymorphisms in the leptin gene in divergent swine breeds] \\ M.A.M. Soares ${ }^{1}$, S.E.F. Guimarães ${ }^{2} *$, R.F. Euclydes ${ }^{2}$, P.S. Lopes $^{2}$, J.O. Peixoto ${ }^{2}$, \\ M.F.M. Guimarães ${ }^{3}$, A.A. Wenceslau ${ }^{4}$, A.V. Pires ${ }^{5}$, A.A. Benevenuto Júnior ${ }^{6}$ \\ ${ }^{1}$ Colegiado de Ciências Biológicas - UNIOESTE - Cascavel, PR \\ ${ }^{2}$ Departamento de Zootecnia - UFV \\ Av. P.H. Rolfs, s/n \\ 36570-000 - Viçosa, MG \\ ${ }^{3}$ Embrapa Gado de Leite - Juiz de Fora - MG \\ ${ }^{4}$ UESC - Santa Cruz, BA \\ ${ }^{5}$ UFVJM - Diamantina, MG \\ ${ }^{6}$ UNITRI - Uberlândia, MG
}

\begin{abstract}
RESUMO
Investigou-se a existência de polimorfismo no gene da leptina (gene da obesidade) entre varrões da raça nativa Piau (porco tipo banha) e matrizes mestiças de raças comerciais (Landrace/Large White e Landrace/Large White com Pietrain), selecionadas para peso e precocidade. Oito pares de primers foram desenhados a partir da seqüência disponível no GenBank (U66254), usada, neste trabalho, como seqüência de referência. Amostras de DNA foram extraídas de células sangüíneas brancas utilizando-se solução de fenol:clorofórmio, após tratamento com proteinase K. Os fragmentos gerados por amplificação da reação em cadeia da polimerase foram purificados e seqüenciados em seqüenciador automático. As seqüências de nucleotídeos, obtidas a partir do DNA das raças comerciais de suíno, apresentaram maior similaridade com a seqüência de referência, e as seqüências geradas a partir do DNA dos animais nativos divergiram de ambas em algumas posições. Dos 28 polimorfismos encontrados, oito foram observados em apenas uma das três seqüências geradas a partir do DNA das raças nativas. Doze estavam presentes em duas seqüências, e os oito polimorfismos restantes foram encontrados nos três animais nativos.
\end{abstract}

Palavras-chave: suíno, leptina, gene da obesidade, polimorfismo

\begin{abstract}
Leptin gene (obese gene) polymorphism was investigated in Piau boars (a fat, native breed) and sows from commercial strains (Landrace/Large White and Landrace/Large White by Pietrain) chosen for rapid growth and early sexual maturity. Eight pairs of primers designed using the sequence available from GenBank (access $n^{\circ}$ U66254) were identified as the reference sequence in this project. DNA samples were extracted from white blood cells using phenol:chloroform solution, after treatment with proteinase $K$. Fragments generated by amplification of the Polymerase Chain Reaction were purified and sequenced in an automatic sequencer. Nucleotide sequences obtained from DNA of commercial swine breeds were similar to the reference sequence; whereas sequences generated from native breed DNA diverged from the reference sequence and from domestic breed DNA. Of the 28 polymorphisms found, eight were observed in only one of the three sequences generated from DNA of native breeds. Twelve polymorphisms were present in two sequences and the eight remaining polymorphisms were found in all three categories of DNA.
\end{abstract}

Keywords: swine, leptin, obese gene, polymorphism

Projeto financiado pela CAPES/PICDT, FAPEMIG e CNPq.

Recebido em 4 de maio de 2004

Aceito em 11 de fevereiro de 2005

*Autor para correspondência (corresponding author)

E-mail: sfacioni@ufv.br 


\section{INTRODUÇÃO}

A leptina, hormônio produzido e secretado pelos adipócitos, influencia diferentes vias metabólicas, alterando o consumo de alimento e o gasto de energia. Zang et al. (1994) identificaram e caracterizaram o gene da leptina (gene $o b$ ) em camundongos. Uma mutação de CGA para TGA $(\mathrm{C} \rightarrow \mathrm{T})$ resulta na substituição de uma arginina na posição 105 para um códon de finalização na leptina, formando uma proteína inacabada, que não é liberada na corrente sangüínea. Camundongos recessivos $(o b / o b)$ são diabéticos, estéreis quando adultos e apresentam gordura corporal acima de $50 \%$ do normal, assemelhando-se à obesidade mórbida em humanos. Leptina recombinante, purificada de Escherichia coli, quando injetada em camundongos ob/ob, reduz o peso corporal, a porcentagem de gordura, o consumo de alimento, a concentração de glicose e a insulina do soro (Pelleymounter et al., 1995) e pode corrigir a esterilidade por reverter a falta de ovulação (Ahima et al., 1996; Chehab et al., 1996), gerando gravidez e parto (Chehab et al., 1996). Desse modo, a leptina funcionaria como sinal endócrino, informando ao cérebro sobre o status nutricional do corpo, influenciando o comportamento alimentar, o metabolismo e o balanço energético do animal (Campfield et al., 1995).

Em suínos, o gene da leptina (gene OB) está localizado no cromossomo 18 (Neuenschwander et al., 1996). O seqüenciamento e o estudo desse gene mostraram três éxons e dois íntrons, estando a seqüência codificadora no segundo e terceiro éxons (Bidwell et al., 1997), e a abundância de seu mRNA está positivamente correlacionada com a porcentagem de gordura corporal desses animais (Bidwell et al., 1997; Ramsay et al., 1998; Robert et al., 1998). Níveis elevados de leptina foram verificados mais em leitões do que em matrizes; estas apresentaram níveis mais altos do que os machos (Robert et al., 1998). Por esse motivo, há sugestão de que a leptina seja um sinalizador entre o status metabólico, o controle neuroendócrino do apetite, o crescimento e a reprodução em suínos (Barb et al., 2002). Também foram relatadas diferenças nos níveis de leptina circulante entre raças de suínos, estando as maiores concentrações nas raças Berkshire $(6.58 \mathrm{ng} / \mathrm{ml})$, Poland China $(6.45 \mathrm{ng} / \mathrm{ml})$ e Landrace (4.77ng/ml), quando comparadas com as concentrações em Chester White, Duroc (3.49ng/ml) e Yorkshire (3.96ng/ml) (Berg et al., 2003).

O estudo do gene da leptina em animais domésticos tem crescido nos últimos anos e, em alguns deles, a busca por polimorfismos neste gene procura responder se as alterações encontradas podem estar correlacionadas com características produtivas e reprodutivas. Em suínos, os relatos sobre detecção de polimorfismo no gene da leptina são esporádicos (Sasaki et al., 1996; Stratil et al., 1997; Robert at al., 1998; Jiang e Gibson, 1999) e, em alguns (Robert at al., 1998; Jiang e Gibson, 1999), há sugestão de relação entre polimorfismo e características de interesse econômico.

A busca por correlações entre os polimorfismos com características de interesse econômico mostrou que o polimorfismo na posição 3.469 (T/C) pode estar associado ao acúmulo de gordura em animais nativos da raça Piau (Borges et al., 1998) e, juntamente com o polimorfismo (A/T) na posição 2.845 , ao consumo de alimento e à velocidade de crescimento em Landrace (Kennes et al., 2001).

Essas observações sugerem que a leptina pode ser um gene candidato para marcar características de interesse econômico, como consumo de alimento, espessura de toucinho, crescimento e reprodução. Assim, diferenças na seqüência de DNA no gene da leptina poderão oferecer mais uma estratégia nos programas de seleção de suínos. O objetivo deste trabalho foi seqüenciar o gene da leptina (gene da obesidade) em raças divergentes de suínos para o fenótipo acúmulo de gordura, visando detectar novos polimorfismos, além dos já relatados.

\section{MATERIAL E MÉTODOS}

Foram analisadas amostras de DNA de 14 animais (11 matrizes e três varrões) da espécie Sus scrofa. Sete matrizes foram obtidas por cruzamento entre animais das raças Landrace e Large White e quatro, por cruzamentos das raças Landrace, Large White e Pietrain, selecionadas para peso e precocidade. Os três varrões eram animais nativos da raça Piau. 
Por meio de punção venosa do sinus orbitalis, $10 \mathrm{ml}$ de sangue foram coletados de cada animal, por gotejamento em tubos estéreis contendo EDTA $0,5 \mathrm{M}, \mathrm{pH} 8,0$, de onde foram isoladas as células brancas, após centrifugação a $2.500 \mathrm{~g}$ durante 20 minutos. A extração do DNA genômico foi realizada por purificação com solução de fenol:clorofórmio, após tratamento com proteinase K, como descrito por Sambrook et al. (1989). Oito pares de primers foram desenhados (Tab. 1) com base na seqüência de nucleotídeos do gene da leptina suína, publicada por Bidwell et al. (1997), número de acesso ao GenBank U66254. Os primers foram selecionados utilizando-se o programa WebPrimers (http://alces.med.umn.edu/bin/

Tabela 1. Seqüência dos primers utilizados para amplificar regiões contíguas do gene da leptina suína, respectiva posição no gene e tamanho esperado em pares de base

\begin{tabular}{|c|c|c|c|}
\hline Número dos pares & Seqüência dos pares de primers $5^{\prime} \rightarrow 3^{\prime}$ & Posição no gene & Tamanho esperado (pb) \\
\hline 1 & $\begin{array}{l}\text { D- CACAGCACAACTCACCGTCG } \\
\text { R- GAACATTCCGGAGACGTGATG }\end{array}$ & 667 a 1398 & 732 \\
\hline 2 & $\begin{array}{l}\text { D- CCTGGGAGACAAGGTCGAAC } \\
\text { R- CACGGAGGGAGTTAACGTGC }\end{array}$ & 1096 a 1675 & 580 \\
\hline 3 & $\begin{array}{l}\text { D- CTCTTCTCAGCTGAGGTCCG } \\
\text { R- AGACGCACCATAAAACTTACGG }\end{array}$ & 1571 a 2027 & 457 \\
\hline 4 & $\begin{array}{l}\text { D- GTGGGGTCCAGATATCCGTT } \\
\text { R- CCAGGCTAGGGGTCTAATCG }\end{array}$ & 1916 a 2519 & 604 \\
\hline 5 & $\begin{array}{l}\text { D- GGTGCAGACAGCTCCGATTA } \\
\text { R- TCAAAGCCACAACCGAAAACT }\end{array}$ & 2486 a 2677 & 192 \\
\hline 6 & $\begin{array}{l}\text { D- CTTCTTGAAAAGTTTTCGGTTGTG } \\
\text { R- CTGTAGAACCAGCCACGACTG }\end{array}$ & 2647 a 3125 & 479 \\
\hline 7 & $\begin{array}{l}\text { D- TGTGAGAAACAGACAGTCGTGG } \\
\text { R- TGAGGATCTGTTGGTAGATCGC }\end{array}$ & 3092 a 3514 & 423 \\
\hline 8 & $\begin{array}{l}\text { D- AACAGAGGGTCACCGGTTTG } \\
\text { R- TTTGGAAGAGCAGCTTAGCG }\end{array}$ & 3416 a 3901 & 486 \\
\hline
\end{tabular}

A amplificação dos fragmentos foi conduzida em um termociclador ${ }^{1}$, utilizando volume final de $20 \mu \mathrm{l}$ contendo 4,0 pmoles de cada primer, $0,2 \mathrm{mM}$ de cada desoxirribonucleotídio (dNTP), 2,0mM de $\mathrm{MgCl}_{2}, 50 \mathrm{mM}$ de $\mathrm{KCl}, 20 \mathrm{mM}$ de Tris- $\mathrm{HCl}$, uma unidade de Taq DNA Polimerase e $25 \mathrm{ng}$ de DNA genômico. O programa consistiu de um passo inicial de desnaturação a $94^{\circ} \mathrm{C}$ por cinco minutos, 35 ciclos de amplificação, compreendendo desnaturação das fitas a $94^{\circ} \mathrm{C}$ por um minuto, ligação dos primers a $66^{\circ} \mathrm{C}$ por um minuto e extensão do fragmento a $72^{\circ} \mathrm{C}$ por um minuto. Ao final, seguiu-se mais um passo de extensão por cinco minutos a $72^{\circ} \mathrm{C}$. Os pares de primers números 4 e 5 tiveram a concentração de $\mathrm{MgCl}_{2}$ elevada para $3 \mathrm{mM}$. Os pares de primers 3,4 e 8 foram amplificados com temperatura de anelamento de $64^{\circ} \mathrm{C}$ e o par número 5 , a $62^{\circ} \mathrm{C}$.

Os fragmentos gerados por amplificação da reação em cadeia pela polimerase (PCR) foram

${ }^{1}$ MJ Research - PTC - 100, Watertown, USA. purificados $^{2}$ e quantificados em espectofotômetro $^{3}$. As reações de seqüenciamento basearam-se na técnica de terminação de cadeia por didesoxinucleotídeos (ddNTPs), descrita por Sanger et al. (1977). Cada reação constou de 200 a 500ng de DNA, $4 \mu 1$ de mix ${ }^{4}$, 5,0 pmoles do primer direto e $6 \mu \mathrm{l}$ de tampão (200mM Tris-HCl pH 9,0; $5 \mathrm{mM} \mathrm{MgCl}$ ) em um volume total de reação de $20 \mu \mathrm{l}$. A mesma reação foi preparada para o primer reverso de cada fragmento. O programa consistiu de um passo inicial de desnaturação a $96^{\circ} \mathrm{C}$ por 30 segundos, ligação dos primers a $59^{\circ} \mathrm{C}$ por 14 segundos e extensão a $60^{\circ} \mathrm{C}$ por quatro minutos, em um total de 35 ciclos.

${ }^{2}$ GlassMax DNA Isolation Matrix System - Life Technologies Inc., Carlsbad, USA.

${ }^{3}$ DNA/RNA GeneQuant II - Amersham Pharmacia Biotech, Buckinghamshire, England.

${ }^{4}$ ABI PRISM BigDye Terminator Cycle Sequencing - PE Applied Biosystems, Foster City, USA. 
O seqüenciamento dos fragmentos purificados foi conduzido em seqüenciador automático ${ }^{5}$. Os dados foram automaticamente convertidos em seqüências de desoxinucleotídeos e montados em contíguos (programa SEQ MAN II DNASTAR Inc.) e, posteriormente, comparados entre si e com a seqüência depositada no GenBank, utilizando-se o programa BLAST (Altschul et al., 1997). Para as análises de restrição dessas sequiências, foi utilizado o programa Webcutter (http://www.firstmarket.com/firstmarket/cutter/).

\section{RESULTADOS E DISCUSSÃO}

Os fragmentos obtidos pela técnica de PCR, quando sobrepostos, compuseram uma região do gene da leptina suína, que compreendeu o final do íntron um, o éxon dois, o íntron dois, o éxon três e uma pequena parte da região $3^{\prime}$ transcrita e não traduzida, gerando, no total, 3.234 pares de base $(\mathrm{pb})$, estando a região codificadora da proteína localizada na maior parte do éxon $2 \mathrm{e}$ todo o éxon 3 (Fig. 1). Todas as seqüências geradas, a partir de amostras de DNA dos 14 animais, foram alinhadas entre si e também com a seqüência publicada por Bidwell et al. (1997), número de acesso ao GenBank: U66254. Todas as numerações atribuídas aos nucleotídeos do gene em estudo foram baseadas na seqüência de referência.

Alguns nucleotídeos do íntron dois do gene da leptina não puderam ser determinados nas amostras de DNA da população em estudo. Assim, devido à interrupção, duas seqüências foram depositadas no GenBank, número de acesso AF477386 e AF 477387: a primeira compreende parte do íntron um, todo o éxon dois e parte do íntron dois, a segunda compreende o restante do íntron dois, todo o éxon três e pequena parte da região $3^{\prime}$ transcrita e não traduzida, de uma das fêmeas (Landrace/Large White). A seqüência de um dos machos da raça nativa Piau também foi depositada no GenBank, com o número de acesso AY079082, e compreende apenas a primeira região mencionada acima, visto que a segunda parte não apresentou variações, excetuando-se na posição 3.787 da região 3' transcrita e não traduzida, em que um dos varrões apresentou a base $\mathrm{T}$ e não a

${ }^{5}$ ABI PRISM 310 Genetic Analyzer - PE Applied Biosystems, Foster City, USA. base $\mathrm{C}$, como verificado nas matrizes e na seqüência de referência.

De maneira geral, as seqüências geradas a partir do DNA das fêmeas mostraram maior similaridade com a seqüência de referência, sendo que as divergências eram muito esporádicas e, quando alguma ocorria, estava presente em apenas uma das matrizes. Nas seqüências obtidas a partir do DNA dos varrões, foram observadas várias substituições de bases quando comparadas tanto com as seqüências das raças comerciais quanto com a seqüência de referência. Essas divergências observadas nos varrões e as respectivas enzimas de restrição que as detectam estão especificadas na Tab. 2 .

Sasaki et al. (1996), ao utilizarem primers degenerados, encontraram polimorfismo no gene da leptina suína ao empregarem a enzima de restrição AciI. Entretanto, esse polimorfismo não pôde ser localizado com precisão nas seqüências geradas neste trabalho. Uma possibilidade seria a substituição de base (T/C) na posição 822 , onde a mesma enzima ganha um sítio quando o alelo C está presente, fato observado em dois varrões. Nessa mesma posição, outro varrão apresentou alelo G, o que acarreta a criação de sítio de restrição para outras enzimas (Bsc4I; BsiYI e $B s(I)$ e exclusão para a enzima anterior.

Outros quatro polimorfismos encontrados neste trabalho já foram relatados em publicações anteriores. Um deles, verificado na posição 3.469 no gene da leptina suína, onde o alelo $\mathrm{T}$ foi encontrado nas seqüências das matrizes e o alelo $\mathrm{C}$ na seqüência de apenas um dos varrões, foi relatado pela primeira vez por Stratil et al. (1997) e, por estar localizado no éxon três, foi alvo de investigação em outros estudos. Jiang e Gibson (1999) sugeriram que o polimorfismo verificado nesta posição, embora não provoque substituição de aminoácidos na proteína, pode estar associado com a espessura de toucinho em suínos. Borges et al. (1998) sugeriram que o alelo C pode estar associado com o acúmulo de gordura, já que a maior freqüência deste ocorreu na raça nativa Piau. Posteriormente, estudos realizados por Kuryl et al. (2003) sugeriram que o genótipo TT pode ser mais vantajoso por estar associado à menor deposição de gordura na carcaça quando comparado com o genótipo TC. Kennes et al. (2001) verificaram que animais da raça Landrace, homozigotos (TT), apresentaram 
pequeno ganho diário de peso a mais, quando comparados com animais heterozigotos TC; uma associação inversa foi verificada por Urban et al. (2002). Maiores estudos serão necessários para verificar se esse polimorfismo está realmente correlacionado com deposição de gordura ou se reflete uma simples variação entre as diferentes raças.

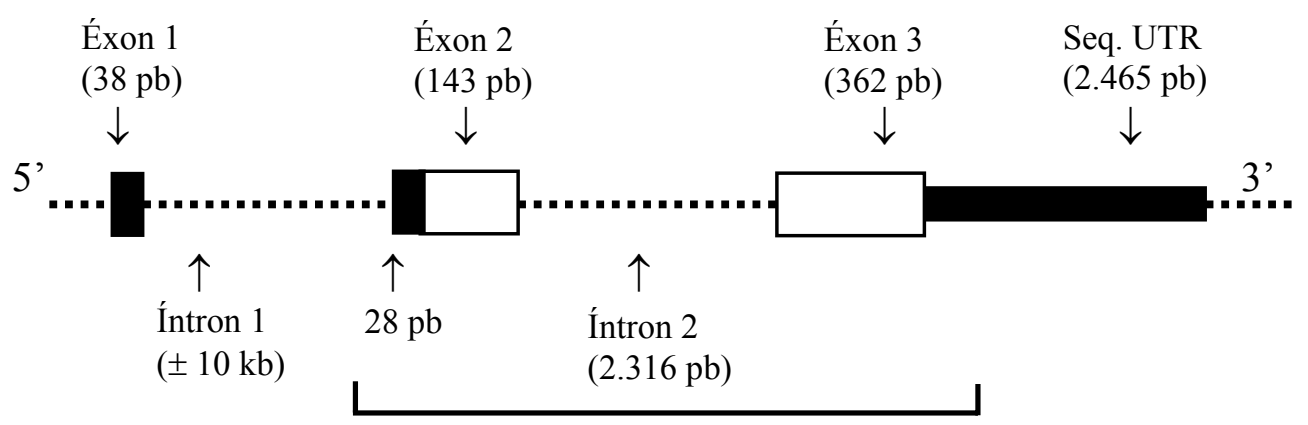

Figura 1. Esquema do gene obeso (OB) de suíno, baseado na descrição de Bidwell et al. (1997). UTR: seqüência transcrita e não traduzida. A chave abaixo da figura indica a região seqüenciada.

Tabela 2. Substituições de bases observadas na seqüência de nucleotídeos do gene da leptina de varrões da raça nativa Piau, em relação às raças comerciais e à seqüência de referência

\begin{tabular}{|c|c|c|c|c|}
\hline $\begin{array}{l}\text { Posição } \\
\text { (U66254) }\end{array}$ & $\begin{array}{c}\text { Nucleotídeo } \\
\text { fêmeas/U66254 }\end{array}$ & $\begin{array}{l}\text { Nucleotídeo } \\
\text { varrões }\end{array}$ & $\begin{array}{l}\text { Exclusão de sítio de } \\
\text { restrição }\end{array}$ & $\begin{array}{l}\text { Inclusão de sítio } \\
\text { de restrição }\end{array}$ \\
\hline 798 & $\mathrm{C}$ & $\mathrm{T}$ & --- & MspA1I; NspBII; PvuII \\
\hline 822 & $\mathrm{~T}$ & $\mathrm{C}$ & --- & $A c i \mathrm{I} ; A c l \mathrm{WI} ; A l w \mathrm{I}$ \\
\hline 822 & $\mathrm{~T}$ & G & --- & $B s c 4 \mathrm{I} ; B s i \mathrm{YI} ; B s l \mathrm{I}$ \\
\hline 828 & $\mathrm{~T}$ & $\mathrm{C}$ & $B s t \mathrm{DEI} ; D d e \mathrm{I}$ & BsaJI; BseDI; BstF5I; FokI \\
\hline $867 *$ & $\mathrm{C}$ & $\mathrm{T}$ & --- & --- \\
\hline 1.112 & G & A & TaqI; TthHB8I & --- \\
\hline $1.326^{*}$ & $\mathrm{~T}$ & $\mathrm{C}$ & --- & --- \\
\hline $1.633^{*}$ & G & A & --- & --- \\
\hline 1.673 & G & A & --- & Hsp92II; NlaIII \\
\hline 1.702 & G & $\mathrm{T}$ & --- & $M s 1 \mathrm{I}$ \\
\hline 1.722 & G & A & MboII & --- \\
\hline $1.850^{*}$ & G & A & --- & --- \\
\hline 1.867 & G & A & SmuI; FauI & --- \\
\hline $1.880^{*}$ & $\mathrm{C}$ & $\mathrm{T}$ & -- & --- \\
\hline $1.884^{*}$ & G & $\mathrm{T}$ & --- & --- \\
\hline $1.904 *$ & G & A & --- & --- \\
\hline 1.913 & A & G & --- & Hin $4 \mathrm{I}$ \\
\hline 1.995 & $\mathrm{~T}$ & $\mathrm{C}$ & --- & AluI; CviJI; MwoI \\
\hline 2.411 & $\mathrm{~T}$ & $\mathrm{C}$ & BamHI; BsaWI; Bst $\mathrm{I}$ & --- \\
\hline 2.845 & A & $\mathrm{T}$ & --- & $X b a \mathrm{I}$ \\
\hline 2.961 & $\mathrm{~T}$ & G & --- & $A c c \mathrm{BSI} ; B s r \mathrm{BI} ; B s t \mathrm{D} 102 \mathrm{I}$ \\
\hline 3.068 & $\mathrm{C}$ & $\mathrm{T}$ & & $D r d \mathrm{I}$ \\
\hline $3.148^{*}$ & G & A & --- & --- \\
\hline 3.266 & $\mathrm{~T}$ & G & --- & BstF5I; FokI \\
\hline 3.297 & G & A & $B s l \mathrm{I} ; B s c 4 \mathrm{I} ; B s i \mathrm{YI}$ & $H p h \mathrm{I} ; M n l \mathrm{I}$ \\
\hline 3.309 & G & A & --- & $A c c \mathrm{I}$ \\
\hline 3.469 & $\mathrm{~T}$ & $\mathrm{C}$ & --- & $\operatorname{HinfI}$ \\
\hline 3.787 & $\mathrm{C}$ & $\mathrm{T}$ & Sth132I & --- \\
\hline
\end{tabular}

* A substituição de base não criou ou excluiu sítio de restrição para as enzimas pesquisadas. 
Robert et al. (1998), ao empregarem enzimas de restrição em DNA genômico, observaram que animais magros apresentavam dois sítios de restrição, um para a enzima HindIII e outro para $B g l \mathrm{II}$. Um outro sítio, para a enzima $X b a \mathrm{I}$, foi detectado tanto em animais obesos quanto em magros. Kennes et al. (2001) caracterizaram esses três polimorfismos, mostrando sua exata localização no gene. O polimorfismo G/A encontrado na posição 2.728 , reconhecido pela primeira enzima, não foi verificado na população em estudo, estando o alelo A presente em todos os animais. $\mathrm{O}$ polimorfismo $\mathrm{A} / \mathrm{T}$, verificado dentro do íntron dois na posição 2.845 e reconhecido pela última enzima, foi observado neste trabalho, representando o segundo polimorfismo que também foi relatado anteriormente por outros autores. $\mathrm{Na}$ população em estudo, o alelo A estava presente nos animais das raças comerciais e o alelo $\mathrm{T}$, nos três animais da raça nativa Piau. $\mathrm{O}$ polimorfismo $\mathrm{T} / \mathrm{C}$ na posição 3.996, reconhecido pela enzima BglII, situado dentro da região $3^{\prime}$ transcrita e não traduzida, não pôde ser avaliado neste trabalho por não ter sido seqüenciado além da base $n^{\circ}$ 3.910 .

Em outros dois polimorfismos (C/T e A/G), verificados nas posições 867 e 1.112, respectivamente, o alelo $\mathrm{T}$ foi observado nos três varrões e o alelo $\mathrm{A}$, em apenas dois. Resultados semelhantes também foram encontrados por Jiang e Gibson (1999), que, ao trabalharem com suínos de raças Chinesas, observaram que, nessas mesmas posições, os alelos $\mathrm{T}$ e A estavam fixados. Esses autores encontraram, ainda, um outro polimorfismo $(\mathrm{G} / \mathrm{T})$ na posição 3.714, região transcrita e não traduzida, onde o alelo $G$ estava fixado nas raças européias. Esse polimorfismo não foi encontrado na população em estudo na qual, embora as fêmeas tenham origem de raças européias, todos os animais apresentaram o alelo $\mathrm{T}$.

Os outros 22 polimorfismos encontrados (Tab. 2) não foram verificados em relatos anteriores e, dentre eles, 15 puderam ser detectados por enzimas de restrição, preditas por análises computacionais. Resultados preliminares (dados não mostrados) têm confirmado algumas dessas enzimas. Assim, dois polimorfismos encontrados na região do íntron um foram confirmados por enzimas de restrição, sendo que, na posição 798, a enzima $P v u I I$ ganhou um sítio de restrição no
DNA dos varrões e, na posição 828 , a enzima DdeI perdeu seu sítio de restrição, ao contrário da enzima FokI que ganhou um sítio. Na região do íntron dois, na posição 2.411, a enzima BamHI perdeu seu sítio de restrição no DNA dos varrões e, na posição 3.266 , a enzima FokI ganhou um sítio. O polimorfismo, na posição 3.469, verificado dentro do éxon 3, também foi confirmado com a enzima Hinfl. Em estudos posteriores, Peixoto et al. (2004), utilizando animais $\mathrm{F}_{2}$, resultantes de cruzamento divergente entre os investigados no presente estudo, encontraram efeito significativo do polimorfismo T/C para as características de consumo de ração, ganho de peso aos 21, 42, 63 e 77 dias $(\mathrm{P}<0,01)$, ganho de peso médio diário e conversão alimentar $(\mathrm{P}<0,05)$, estando o alelo $\mathrm{C}$ associado às piores médias fenotípicas.

Com relação ao polimorfismo na posição 1.995 , testado com a enzima $A l u \mathrm{I}$, o resultado não foi o esperado. Isto sugere falha na edição das seqüências de nucleotídeos geradas pelo seqüenciador automático, visto que apenas um dos animais nativos apresentou este polimorfismo, o que possivelmente poderia ser contornado com uma reavaliação por outros programas.

De maneira geral, as variações encontradas na seqüência de nucleotídeos dos varrões puderam ser agrupadas conforme sua ocorrência. Assim, as substituições de bases observadas nas posições 798 (C/T), 822 (T/C), 1.673 (G/A), 1.884 (G/T), 1.995 (T/C), 3.309 (G/A), 3.469 (T/C) e 3.787 $(\mathrm{C} / \mathrm{T})$ estavam presentes na seqüência de nucleotídeos de apenas um animal da raça nativa Piau, enquanto que as substituições verificadas nas posições $822(\mathrm{~T} / \mathrm{C}), 828(\mathrm{~T} / \mathrm{C}), 1.112(\mathrm{G} / \mathrm{A})$, 1.633 (G/A), 1.702 (G/T), 1.850 (G/A), 1.867 (G/A), 1.880 (C/T), 1.904 (G/A), 2.411 (T/C), $2.961(\mathrm{~T} / \mathrm{G})$ e $3.068(\mathrm{C} / \mathrm{T})$ estavam presentes em dois varrões. Os polimorfismos encontrados nas posições 867 (C/T), $1.326(\mathrm{~T} / \mathrm{C}), 1.722$ (G/A), 1.913 (A/G), 2.845 (A/T), 3.148 (G/A), 3.266 $(\mathrm{T} / \mathrm{G})$ e 3.297 (G/A) foram verificados nas seqüências dos três varrões ao mesmo tempo. Embora todas essas variações estejam ocorrendo em regiões de íntron, podem representar potenciais marcadores, visto que ocorreram exclusivamente nos varrões nativos. A utilização destes polimorfismos como marcadores deverá ser avaliada, buscando-se correlações com consumo alimentar, ganho de peso, espessura de 
toucinho ou alguma outra característica produtiva ou reprodutiva, assim como nos estudos de Borges et al. (1998), Jiang e Gibson (1999), Kennes et al. (2001), Urban et al. (2002), Kuryl et al. (2003) e Peixoto et al. (2004) com o polimorfismo T3469C. Estudos adicionais serão necessários para verificar se as outras variações estão simplesmente refletindo diferenças entre as raças ou se podem estar relacionadas, de alguma maneira, com características produtivas e reprodutivas em suínos.

\section{REFERÊNCIAS BIBLIOGRÁFICAS}

AHIMA, R.S.; PRABAKARAN, D.; MANTZOROS, C. et al. Role of leptin in the neuroendocrine response to fasting. Nature, v.382, p.250-252, 1996.

ALTSCHUL, S.F.; MADDEN, T.L.; SCHÄFFER, A.A. et al. Gapped BLAST and PSI-BLAST: a new generation of protein database search programs. Nucleic Acids Res. v.25, p.3389-3402, 1997.

BERG, E.P.; McFADIN, E.L.; MADDOCK, K.R. et al. Serum concentrations of leptin in six genetic lines of swine and relationship with growth and carcass characteristics. J. Anim. Sci., v.81, p.167-171, 2003.

BIDWELL, C.A.; JI, S.; FRANK G.R. et al. Cloning and expression of the porcine obese gene. Anim. Biotechnol., v.8, p.191-206, 1997.

BORGES, G.S.N.; SANTANA, B.A.A.; FRANCO, M.M. et al. Determinação das freqüências alélicas do gene da obesidade em diferentes raças suínas. Genet. Molec. Biol., v.21, suppl., p.89, 1998. (Abstract).

CAMPFIELD, L.A.; SMITH, F.J.; GUISEZ, Y. et al. Recombinant mouse $\mathrm{OB}$ protein: evidence for a peripheral signal linking adiposity and central neural networks. Science, v.269, p.546-549, 1995.

CHEHAB, F.F.; LIM, M.E.; LU, R. Correction of the sterility defect in homozygous obese female mice by treatment with the human recombinant leptin. Nature Genet., v.12, p.318-320, 1996.

JIANG, Z-H.; GIBSON, J.P. Genetic polymorphisms in the leptin gene and their association with fatness in four pig breeds. Mammalian Genome, v.10, p.191-193, 1999.

KENNES, Y.M.; MURPHY, B.D.; POTHIER, F. et al. Characterization of swine leptin (LEP) polymorphisms and their association with production traits. Anim. Genet., v.32, p.215-218, 2001.

KURYL, J.; KAPELANSKI, W.; PIERZCHALA, M. et al. A relationship between genotypes at the GH and LEP loci and carcass meat and fat deposition in pigs. Anim. Sci. Pap. Rep., v.21, p.15-26, 2003.
NEUENSCHWANDER， S.; RETTENBERGER， G.; MEIJERINK, E. et al. Partial characterization of porcine obesity gene (OBS) and its localization to chromosome 18 by somatic cell hybrids. Anim. Gen., v.27, p.275-278, 1996.

PEIXOTO, J.O.; GUIMARÃES, S.E.F.; LOPES, P.S. et al. Associação do polimorfismo $\mathrm{T} 3469 \mathrm{C}$ do gene da leptina com características de desempenho em suínos. In: SIMPÓSIO DA SOCIEDADE BRASILEIRA DE MELHORAMENTO ANIMAL, 5., 2004, Pirassununga, SP. Disponível em SC, editado pela Soc. Bras. de Melhoramento Animal, 2004 (Resumo expandido).

PELLEYMOUNTER, M.A.; CULLEN, M.J.; BAKER, M.B. et al. Effects of the obese gene product on body weight regulation in $o b / o b$ mice. Science, v.269, p.540$543,1995$.

RAMSAY, T.G.; YAN, X.; MORRISON, C. The obesity gene in swine: sequence and expression of porcine leptin. J. Anim. Sci., v.76, p.484-490, 1998.

$\begin{array}{llll}\text { RESTRICTION } & \text { ENZYME } & \text { DATABASE } & \text { - } \\ \text { WEBCUTTER } & \text { [1997]: } & \text { Disponível } & \text { em }\end{array}$ $<$ http://www.firstmarket.com/firstmarket/cutter/>.

Acessado em: 26 mar. 2001.

ROBERT, C.; PALIN, M-F.; COULOMBE, N. et al. Backfat thickness in pigs is positively associated with leptin mRNA levels. Can. J. Anim. Sci., v.78, p.473-482, 1998.

SAMBROOK, J.; FRITSCH, E.F.; MANIATIS, T. Molecular cloning: a laboratory manual. 2.ed. New York: Cold Spring Habor Laboratory, 1989. 564p.

SANGER, F.; NICKLEN, S.; COULSON, A.R. DNA sequencing with chain-terminating inhibitors. Proceedings of the National Academy of Sciences of the United States of America, v.74, p.5463-5467, 1977.

SASAKI, S.; CLUTTER, A.C.; POMP, D. Assignment of the porcine obese (leptin) gene to chromosome 18 by linkage analysis of a new PCR-based polymorphism. Mammalian Genome, v.7, p.471-472, 1996.

STRATIL, A.; PEELMAN, L.; POUCKE, M.V. et al. A Hinfl PCR-RFLP at the porcine leptin (LEP) gene. Anim. Gen., v.28, p.371-372, 1997.

URBAN, T.; KUCIEL, J.; MIKOLÁSOVÁ. Polymorphism of genes encoding for ryanodine receptor, growth hormone, leptin and MYC protooncogene protein and meat production in Duroc pigs. Czech. J. Anim. Sci., v47, p.411-417, 2002.

VIRTUAL GENOME CENTER. 1997. Disponível em: $<$ http://alces.med.umn.edu/bin/webprimers $>$. Acessado em: 3 abr. 1998.

ZHANG, F.; BASINSKI, M.B.; BEALS, J.M. et al. Crystal structure of the obese protein leptin-E100. Nature, v.387, p.206-209, 1997. 